\title{
Developing a Facility Location Model for Reducing Costs Before and After Enemy Attack
}

\author{
Hasan Hosseini-Nasab*, Saeed Abedi \\ Department of Industrial Engineering, Yazd University, Yazd, Iran \\ Email address: \\ hhn@yazd.ac.ir (H. Hosseini-Nasab) \\ *Corresponding author:
}

To cite this article:

Hasan Hosseini-Nasab, Saeed Abedi. Developing a Facility Location Model for Reducing Costs Before and After Enemy Attack. American Journal of Applied Scientific Research. Vol. 3, No. 5, 2017, pp. 56-62. doi: 10.11648/j.ajasr.20170305.12

Received: April 19, 2017; Accepted: May 25, 2017; Published: November 28, 2017

\begin{abstract}
Site selection is one of the main principles of the passive defense. A multiple objective and nonlinear programming formulation which considers the principles of passive defense site selection according to both qualitative and quantitative aspects is proposed in this paper. The aim is to reduce the site selection costs while the security of network formed by the facilities is maximized, and to reduce the costs of the network after being attacked. To solve the proposed model, a GATOPSIS method is proposed.
\end{abstract}

Keywords: Passive Defense, Mathematical Programming, Genetic Algorithm

\section{Introduction}

Issues related to facility location and layout, have been studied for centuries. To explain this issue should be said that a special state of location has been solved in the early $17^{\text {th }}$ century. Although many of scientists concerned to facility location and layout problems for years, and by development of operations research, again necessity of considering this problem was felt. These days, a lot of scientists are interested to facility location and layout $[7,8]$.

So far, economists, operational researchers, urban designers, scientists of management science, architects, ecologists and engineers in various fields have realized that there is common interest to facility location and layout in their field. Each of those groups has been tend to a different explanation of this topic and recommended different ways to solve it. In fact, each of them has different explanation for facility [16, 17, 19].

Facility location or site selection is a kind of spatial planning during which the place of establishment will be determined. In the usual spatial planning, first the features of the zones is determined and then depending on their features and specifications, the activity or the activities that are suitable for each zone is determined. But in site selection, first the features of a particular activity is determined and then the places and zones that are more suitable for the determined activities will be assigned [11].

The beginning of the industrial site selection goes back to 1909 when Wesolowski published his book The Weber Problem, in this regard [28]. In this book, he presented his paper findings on factorial industries. He took the fallowing three factors as the influential elements in industrial site selection [25].

(1) Workforce costs

(2) Transportation costs

(3) Association forces or non-association of the transportation costs

In 1984, Sorensen [26] suggested his work in terms of Sweet for the Sour. In comparison with Weber, he divided the costs more realistically to the cost of transportation and production.

In recent years, the principle of site selection has been more emphasized and the scientists have proposed many theories on this domain [3, 10, 23, 27]. In traditional microeconomic theory, the firm is defined as a productive unit which seeks to maximize profit through production and sales, so most of researchers in this context only focus on the system costs. Their results can not solely be applied in passive defense issues because they do not pay attention to the security of facilities places, limitation of their distances, their dispersion to increase the covered areas and reduce their 
recognize-ability by the enemy and avoid impairment of production network because of being closeness. If the facilities be placed near each other, they may be attacked in an inroad [6].

One of the defining objectives in location science is to maximize dispersion. Facilities can be dispersed for a wide variety of purposes, including keeping competitors of the same franchise system apart, dispersing criminal rehabilitation facilities from population centers, and locating nuclear power plants in such a way as to maximize security [9].

By far the most common use of dispersion models is for the location of undesirable facilities [5, 7-9, 12-15, 22].

Berman and Gavious [4], proposed in 2007, they coped with the examining the costs of system helping the government in order to resist against the terrorist attacks and also examining the cost of these attacks. The issue was considered in a way that the process of location was shaped like a game between terrorist and government so that both make up their minds by being aware of one another' action. Terrorist by being aware of the location of the aid systems attacks such places in order to enhance reconstructing costs of government and government tries to reduce the cost resulted by the attacks and also the costs of location and setting up utility. Therefore, by the use of the theory of games the problem is solved.

According to these reasons the necessity to a research which considers the principles of location in terms of passive defense attends the costs of attacks in future is essential.

\section{Passive Defense and the Necessity of Considering Location}

A review on statistics and recorded evidence of the previous wars, confirms that because of following reasons, critical facilities will turn to simple objectives for a successful targeting by enemy:

A technological gap between modern offensive weapon of the enemy and our defensive weapons

The vulnerability of air defense against the electronic war

Astonishing these systems by attacking airplanes and ballistic and cruise missiles

Lunching missiles beyond the access of air defenses, lack of anti-missile weapons

Because of these reasons, following the principles of passive defense and performing it in countries is essential. One of the main principles to fulfill the objectives of passive defense is location principle.

According to the proposed identification in the passive defense domain, site selection is: selecting the best and the most appropriate place for establishment in a way that it enables us to hide human force, facilities and activities appropriately. Thus, if site selection is done well, it minimizes the necessity to use artificial tools for camouflage [20].

The experience has shown that an appropriate and suitable site selection can solve many problems related to camouflage and concealment and also reduce the possible threats and vulnerabilities. Some advantages of an appropriate site selection are as follows:

(1) The significant reduction of vulnerability

(2) Creation a suitable defensive situation

(3) Confronting the enemy with problems and limitations in his attacks and disable it to do any process

(4) The reduction of dependency to defensive armaments

In passive defense, site selection includes three bases: duty, dispersion and topography [24].

Dispersion is the distribution and decentralization of the forces, facilities, installations or domestic activities to reduce their vulnerability against threats. The main requirement in dispersion principle is the largeness and extent of a position. Since the dispersion of the facilities and installation makes the selected site vulnerable, it is necessary to disperse the facilities, facilities and installations.

Considering the above principles and rules, a site should be selected for facilities and installations so that it can satisfy the requirements of the passive defense. In the same way, a model is needed to select the required site of the facilities and installations that can formulate all the limitations and demands.

The Purpose of this paper is to develop a model for facility location based on passive defense and a solution method for it that can be applicable against Wardens theory. So the proposed model tries to maximize the facilities dispersion measure. It can do so by maximization of the set of measured spatial (Euclidean) weighted distances. It should, also, select the sites that have reliability. This reliability refers to the ability to perform the duty and harmony with the environment. Additionally, the facilities transportation, location and production costs and cost of possible attacks to them must be minimized.

The rest of this paper organized as follows: In the following section, the necessity of site selection in the passive defense will be explained and then analyze the problem and its requirements and the way of fulfilling them. Analysts also deal with the limitations of the problem and the reason of their existence. In section 4, we make the hypotheses, nomenclature and present the proposed model. In section 5 , the conclusion of the proposed model will be offered in a unique unit and a numerical example will be solved. And then, the results and the model capabilities, in comparison with other models, will be analyzed.

\section{Problem Definition}

In this problem, there are some places which are placed in one region. Their longitudinal and latitudinal distances (longitudinal and latitudinal coordinates) from a refer point is clear. These points, also, have a feature, named security coefficient that depends on some factors, including the ability of the points to help us to do our duty, the harmoniousness of the facilities with the environment, hiding the facilities from the enemy and other influential parameters that enables the 
enemy to identify the facilities. It is calculated by multiplying two above parameters by another one, named criticality (gravity).

Above parameters define as follows:

Duty: the ability to correctly perform the duty based on the facilities in a region that is identified with a number between zero and one. The more this number is for a facility; the more that facility has the ability is to perform his duty in that certain point.

Criticality: it shows the intensity of the effects of enemy's attack on especial facility on the whole system and the usual circulation of the people life. The value of the criticality can be shown by a numerical parameter. The more severe effect of the attack, the less the value of this parameter.

Recognition: the possibility of the recognition of the site selected facility in that place according to the influential factors in recognition of a facility by enemy's offensive armaments. The more measure of recognition, the less the value of this number.

These places have some distances too that are different from their spatial distances. They are the same distances that must be traversed by the land forces that are busy with the system so that they can move from one place to another.

In this issue, there are two kinds of interaction between the facilities that are defined as follows:

Repulsion interaction (disagreement): it is identified by a number between zero and one. The less this number is, the more disagreement will be between those two facilities. This interaction shows that whether these two facilities should be placed far from each other or no. This coefficient is imposed on the system by the essence two facilities application, official policies and other influential factors.

The interaction of the synergetic relationship between two facilities: it is also identified by a number between zero and one that shows the relation weight between two facilities. The greater the value of this coefficient, there are more transportations between these two facilities and thus, the cost of the distance between two facilities.

Because of some spatial limitations and some other factors, the maximum air distance between different kinds of facilities should determine. These distances are even defined for similar facilities.

Our objectives in this model are: achieve the maximum dispersion with a focus on maximization of the sum of weighted distances by repulsion coefficients. This purpose seeks to make the created network by site selected facilities, provide the dispersion principle in the passive defense and also be dispersed through the entire network.

Minimization the system transportation cost which identified by synergetic relationship coefficient.

Achieve the maximum security coefficient of the selected sites, minimizing the total cost included fixed and variable (production) costs and minimizing the expected cost of attack to facilities.

\subsection{Assumptions}

(1) It is supposed that the number of the facilities is less or equal to the number of all the sites

(2) The land distances cannot be less than air distances

(3) The presented repulsion coefficients are taken from the system specialists and experts

(4) The synergetic relationship coefficient shows the coming and going cost according to the distance between two facilities. These coming and going can be due to non-production relationships too

(5) The facilities that are in the process of site selection must be kept in a certain distance from each other. Because they may have poisonous and flammable material

(6) The reference point is not a part of selected sites, but it is located at the low and left of all the sites

(7) Except the facility site determination variable, other features and parameters related to the sites, facilities, costs and coefficients are known parts of the issue

(8) All the distances are specified in a center to center mode

(9) All demands most be satisfied

\subsection{Definitions}

(1) The set of selected points (P) has the following features for site selection:

(2) Longitudinal coordinate that shows the sites distance from the reference point on the $\mathrm{X}$ axis in the coordinate system.

(3) Latitudinal coordinate that shows the sites distance from the reference point on the $\mathrm{Y}$ axis in the coordinate system.

(4) Each two places have a distance from each other that must be traversed on the land.

(5) The total number of the selected sites is clean cut.

(6) Fixed and variable costs both depend on the facility type and the selected site.

(7) The set of different kind of facilities in site selection (t) have the following features:

(8) The repulsion coefficient between facilities is based on their kind not their places.

(9) The weight coefficient, also, is changed based on the kind of facilities and not their places.

(10)In site selection, the number of every kind of facility is certain.

\subsection{Nomenclatures}

In order to define the considered model, the following symbols are used:

$N:$ The total number of the selected sites.

$t$ : The number of the kind of facilities.

$X_{i}$ : The longitudinal coordinate of the selected site $\mathrm{i}$.

$Y_{i}$ : The latitudinal coordinate of the selected site $\mathrm{i}$.

$d_{i j}$ : The distance between two selected sites, $\mathrm{i}$ and $\mathrm{j}$, that ranges from 1 to $\mathrm{N}$.

$R_{K L}$ : The repulsion coefficient between $\mathrm{k}$ and 1 facilities that ranges from 1 to $t$. 
$W_{K L}$ : The cost of communication between $\mathrm{k}$ and 1 facilities that ranges according to the distance unit.

$F_{i K}$ : The fixed cost of placing facility type $\mathrm{k}$ in site $\mathrm{i}$.

$V_{i K}$ : The variable cost of producing one unit of production of facility type $\mathrm{k}$ in site i. ik V

$P_{i K}$ : The capacity for production of facility type $\mathrm{k}$ in site $\mathrm{i}$.

$Q_{K}$ : The demand for production of facility type k.

$H_{K}$ : The maximum number of facility type $\mathrm{k}$.

$M D_{K L}$ : The minimum distance between facilities of type $\mathrm{k}$ and 1 .

$S e_{i K}$ : The security coefficient of the place $i$ for the facility $\mathrm{k}$ that ranges from zero to one.

$\alpha_{i}$ : The function weight of the objective functions in the TOPSIS.

$A_{K}$ : Probability of attack to facility type k.

$S u_{i K}$ : Probability of success of attack to facility type k in site I that equals with $1-S e_{i K}$.

$M_{i K}$ : Cost of reconstruction of facility type $\mathrm{k}$ in site $\mathrm{i}$ that equals to $F_{i K}$.

$N_{i K}$ : Cost of dysfunction of facility type k in site i.

The decision variable of the following model is defined as follows:

$$
Z_{i k}\left\{\begin{array}{lr}
1: \text { if } & \text { facility type } k \text { locates in site } i \\
0: & \text { Otherwise }
\end{array}\right.
$$

\subsection{Formulation of Model}

Because the mentioned purposes cannot be explained with a single objective function and in some cases have

contradictory with each other, the issue just can be represented as a multi-objective model. Therefore, the problem is formulated as follows:

The objective function (1) is to maximizing the sum of weighted Euclidean distances by the repulsion coefficient that tries to maximizing the dispersion of network. The objective function (2) is to minimizing weighted distances by the weight of interactional relationships. The (3) is the objective function of minimizing the fixed and variable costs of production in all sites.

The objective function (4) maximizing the total security coefficient of the selected network.

The restrictions (5) are to have confidence that there is only one facility in each place. The restrictions (6) are to have confidence that all kinds of facilities are located and the restrictions (7) observing the air distance limitations between the facilities. The restriction set (8) guarantee that the demand of customers to be satisfied.

Using this form makes the calculations simple and the problem of site selection in passive defense will change the qualitative form of problem to a quantitative form that the understanding of this form is much easier than qualitative form.

$$
\begin{gathered}
Z_{1}=\operatorname{Max} \sum_{i=1}^{N} \sum_{j=1}^{N} \sqrt{\left(X_{i}-X_{j}\right)^{2}+\left(Y_{i}-Y_{j}\right)^{2}} \times\left[\sum_{k=1}^{t} \sum_{l=1}^{t} Z_{i k} Z_{j l} Q_{k l}\right] \\
Z_{2}=\operatorname{Min} \sum_{i=1}^{N} \sum_{j=1}^{N} d_{i j} \times\left[\sum_{k=1}^{t} \sum_{l=1}^{t} Z_{i k} Z_{j l} W_{k l}\right] \\
Z_{3}=\operatorname{Min} \sum_{i=1}^{n} \sum_{k=1}^{t}\left(F_{i k}+V_{i k} \times C_{i k}\right) \times Z_{i k}
\end{gathered}
$$

Considering the following restrictions:

$$
\begin{gathered}
\sum_{k=1}^{t} Z_{i k} \leq 1 \quad \forall i=1, \ldots, N \\
\sum_{i=1}^{N} Z_{i k}=H_{k} \quad \forall k=1, \ldots, t \\
\sqrt{\left(\left(X_{i}-X_{j}\right)^{2}+\left(Y_{i}-Y_{j}\right)^{2}\right)} \times Z_{i k} \times Z_{j l} \geq M_{k l} \\
, \forall i=1, \ldots, N-1, i+1 \leq j \leq N, k, l=1, \ldots, t, Z_{i k}=Z_{j l}=1
\end{gathered}
$$

\section{Numerical Example}

Consider a situation which there is 6 types of facilities to be located in 13 sites and other parameters of example are shown in Tables 1 to 12. This problem has been solved with 
proposed method and presented results in Table 13 obtained and to showing the applicability of proposed algorithm the results is compared with achieved results from Lingo with the same method.

Table 1. The objective function's weights in TOPSIS $\left(\alpha_{i}\right)$.

\begin{tabular}{lllllll}
\hline Obj. 1 & Obj. 2 & Obj. 3 & Obj. 4 & Obj. 5 & Obj. 6 & Penalty \\
\hline 0.2 & 0.1 & 0.1 & 0.2 & 0.2 & 0.2 & 1.0 \\
\hline
\end{tabular}

Table 2. The fixed cost of site selection $\left(F_{i k}\right)$.

\begin{tabular}{|c|c|c|c|c|c|c|}
\hline $\begin{array}{ll} & \text { Facility Type } \\
\end{array}$ & 1 & 2 & 3 & 4 & 5 & 6 \\
\hline 1 & 219 & 205 & 281 & 253 & 229 & 231 \\
\hline 2 & 289 & 249 & 274 & 217 & 254 & 210 \\
\hline 3 & 225 & 224 & 208 & 246 & 242 & 234 \\
\hline 4 & 271 & 267 & 213 & 235 & 218 & 266 \\
\hline 5 & 227 & 268 & 289 & 253 & 244 & 266 \\
\hline 6 & 296 & 267 & 220 & 259 & 259 & 243 \\
\hline 7 & 241 & 216 & 229 & 203 & 210 & 283 \\
\hline 8 & 263 & 293 & 254 & 237 & 223 & 211 \\
\hline 9 & 210 & 282 & 229 & 268 & 249 & 282 \\
\hline 10 & 209 & 230 & 206 & 270 & 247 & 239 \\
\hline 11 & 291 & 260 & 272 & 245 & 270 & 217 \\
\hline 12 & 282 & 214 & 244 & 274 & 267 & 299 \\
\hline 13 & 259 & 288 & 248 & 297 & 253 & 207 \\
\hline
\end{tabular}

Table 3. The variable cost of production one unit in places by facilities $\left(V_{i k}\right)$.

\begin{tabular}{|c|c|c|c|c|c|c|}
\hline Site Facility Type & 1 & 2 & 3 & 4 & 5 & 6 \\
\hline 1 & 26.1 & 21.1 & 27.1 & 22.6 & 23.6 & 24.3 \\
\hline 2 & 20.6 & 26.4 & 25.6 & 24 & 26.9 & 24.3 \\
\hline 3 & 23.2 & 21.3 & 21.9 & 20.8 & 23 & 21.3 \\
\hline 4 & 27.8 & 21.4 & 22.2 & 26.9 & 25.4 & 20.3 \\
\hline 5 & 27 & 21 & 20.8 & 24.1 & 28.4 & 23 \\
\hline 6 & 21.3 & 21.5 & 29.2 & 29.9 & 26 & 23.2 \\
\hline 7 & 21.4 & 21.7 & 27.1 & 24.1 & 23.4 & 26.6 \\
\hline 8 & 21 & 22 & 25.6 & 26.3 & 23 & 29.6 \\
\hline 9 & 20.1 & 23.2 & 23.2 & 21.6 & 24.6 & 29.4 \\
\hline 10 & 24.3 & 23.2 & 21.7 & 23.9 & 24.3 & 24.6 \\
\hline 11 & 26.6 & 22.2 & 26.3 & 21.7 & 23.6 & 22.5 \\
\hline 12 & 27.3 & 22.6 & 29.9 & 27.6 & 25.6 & 27.7 \\
\hline 13 & 25.4 & 29 & 21.8 & 28.8 & 27.5 & 27.6 \\
\hline
\end{tabular}

Table 4. Security Coefficient of facilities in sites $\left(S_{i k}\right)$.

\begin{tabular}{|c|c|c|c|c|c|c|}
\hline Site Facility Type & 1 & 2 & 3 & 4 & 5 & 6 \\
\hline 1 & 0.66 & 0.84 & 0.15 & 0.85 & 0.17 & 0.79 \\
\hline 2 & 0.73 & 0.21 & 0.19 & 0.87 & 0.62 & 0.51 \\
\hline 3 & 0.89 & 0.55 & 0.04 & 0.27 & 0.57 & 0.18 \\
\hline 4 & 0.98 & 0.63 & 0.64 & 0.21 & 0.05 & 0.4 \\
\hline 5 & 0.77 & 0.03 & 0.28 & 0.56 & 0.93 & 0.13 \\
\hline 6 & 0.58 & 0.61 & 0.54 & 0.64 & 0.73 & 0.03 \\
\hline 7 & 0.03 & 0.99 & 0.06 & 0.56 & 0.9 & 0.51 \\
\hline 8 & 0.84 & 0.54 & 0.52 & 0.18 & 0.2 & 0.76 \\
\hline 9 & 0.56 & 0.71 & 0.34 & 0.6 & 0.09 & 0.63 \\
\hline 10 & 0.85 & 1 & 0.18 & 0.3 & 0.31 & 0.09 \\
\hline 11 & 0.35 & 0.29 & 0.21 & 0.13 & 0.46 & 0.08 \\
\hline 12 & 0.45 & 0.41 & 0.91 & 0.21 & 0.1 & 0.78 \\
\hline 13 & 0.75 & 0.01 & 0.05 & 0.67 & 0.6 & 0.53 \\
\hline
\end{tabular}

Table 5. Production capacity of facilities in sites $\left(P_{i k}\right)$.

\begin{tabular}{|c|c|c|c|c|c|c|}
\hline Site Facility Type & 1 & 2 & 3 & 4 & 5 & 6 \\
\hline 1 & 34 & 67 & 70 & 95 & 20 & 73 \\
\hline 2 & 79 & 95 & 47 & 68 & 16 & 18 \\
\hline 3 & 27 & 29 & 86 & 53 & 46 & 57 \\
\hline 4 & 36 & 74 & 85 & 68 & 50 & 58 \\
\hline 5 & 18 & 31 & 33 & 59 & 43 & 88 \\
\hline 6 & 62 & 21 & 65 & 68 & 79 & 54 \\
\hline 7 & 63 & 50 & 83 & 88 & 58 & 94 \\
\hline 8 & 34 & 12 & 78 & 99 & 18 & 73 \\
\hline 9 & 14 & 40 & 44 & 56 & 20 & 62 \\
\hline 10 & 78 & 48 & 29 & 90 & 22 & 83 \\
\hline 11 & 32 & 34 & 81 & 63 & 71 & 89 \\
\hline 12 & 50 & 28 & 95 & 24 & 55 & 99 \\
\hline 13 & 82 & 31 & 55 & 91 & 62 & 36 \\
\hline
\end{tabular}

Table 6. Minimum required Euclidean distances between facilities $\left(M D_{k l}\right)$.

\begin{tabular}{lllllll}
\hline & Type 1 & Type 2 & Type 3 & Type 4 & Type 5 & Type 6 \\
\hline Type 1 & 10 & 11 & 13 & 30 & 15 & 18 \\
Type 2 & 10 & 24 & 14 & 15 & 21 & 24 \\
Type 3 & 15 & 25 & 12 & 14 & 13 & 17 \\
Type 4 & 14 & 19 & 14 & 13 & 24 & 16 \\
Type 5 & 10 & 20 & 15 & 20 & 12 & 20 \\
Type 6 & 10 & 20 & 13 & 15 & 13 & 20 \\
\hline
\end{tabular}

Table 7. Demand for each production type $\left(Q_{k}\right)$.

\begin{tabular}{llllll}
\hline Type 1 & Type 2 & Type 3 & Type 4 & Type 5 & Type 6 \\
\hline 34 & 24 & 36 & 50 & 63 & 34 \\
\hline \multicolumn{6}{l}{ Table 8. Maximum available of facilities $\left(H_{k}\right)}$. \\
\hline Type 1 & Type 2 & Type 3 & Type 4 & Type 5 & Type 6 \\
\hline 4 & 2 & 4 & 2 & 5 & 2 \\
\hline
\end{tabular}

Table 9. Repulsion coefficient between facilities $\left(R_{k l}\right)$.

\begin{tabular}{lllllll}
\hline & Type 1 & Type 2 & Type 3 & Type 4 & Type 5 & Type 6 \\
\hline Type 1 & 0.13 & 0.8 & 0.74 & 0.95 & 0.28 & 0.51 \\
Type 2 & 0.91 & 0.14 & 0.39 & 0.03 & 0.68 & 0.7 \\
Type 3 & 0.63 & 0.42 & 0.66 & 0.44 & 0.66 & 0.89 \\
Type 4 & 0.1 & 0.92 & 0.17 & 0.38 & 0.16 & 0.96 \\
Type 5 & 0.28 & 0.79 & 0.71 & 0.77 & 0.12 & 0.55 \\
Type 6 & 0.55 & 0.96 & 0.03 & 0.8 & 0.5 & 0.14 \\
\hline
\end{tabular}

Table 10. Cost of communication between facilities $\left(C_{k l}\right)$.

\begin{tabular}{lllllll}
\hline & Type 1 & Type 2 & Type 3 & Type 4 & Type 5 & Type 6 \\
\hline Type 1 & 0.24 & 0.37 & 0.23 & 0.74 & 0.45 & 0.88 \\
Type 2 & 0.12 & 0.11 & 0.35 & 0.19 & 0.31 & 0.55 \\
Type 3 & 0.18 & 0.78 & 0.82 & 0.69 & 0.51 & 0.62 \\
Type 4 & 0.24 & 0.39 & 0.02 & 0.18 & 0.51 & 0.59 \\
Type 5 & 0.42 & 0.24 & 0.04 & 0.37 & 0.82 & 0.21 \\
Type 6 & 0.05 & 0.4 & 0.17 & 0.63 & 0.79 & 0.3 \\
\hline
\end{tabular}


Table 11. Transportation distances between candidate sites $\left(D_{i j}\right)$.

\begin{tabular}{|c|c|c|c|c|c|c|c|c|c|c|c|c|c|}
\hline Site Site & 1 & 2 & 3 & 4 & 5 & 6 & 7 & 8 & 9 & 10 & 11 & 12 & 13 \\
\hline 1 & 0 & 70 & 117 & 48 & 75 & 137 & 57 & 50 & 193 & 35 & 36 & 71 & 63 \\
\hline 2 & 70 & 0 & 59 & 126 & 45 & 84 & 57 & 148 & 72 & 26 & 40 & 79 & 83 \\
\hline 3 & 117 & 59 & 0 & 111 & 43 & 50 & 106 & 114 & 32 & 97 & 81 & 52 & 52 \\
\hline 4 & 48 & 126 & 111 & 0 & 100 & 144 & 107 & 9 & 154 & 59 & 83 & 73 & 72 \\
\hline 5 & 75 & 45 & 43 & 100 & 0 & 81 & 66 & 113 & 90 & 53 & 51 & 82 & 53 \\
\hline 6 & 137 & 84 & 50 & 144 & 81 & 0 & 143 & 216 & 25 & 132 & 113 & 91 & 70 \\
\hline 7 & 57 & 57 & 106 & 107 & 66 & 143 & 0 & 74 & 101 & 16 & 9 & 101 & 108 \\
\hline 8 & 50 & 148 & 114 & 9 & 113 & 216 & 74 & 0 & 211 & 122 & 65 & 103 & 100 \\
\hline 9 & 193 & 72 & 32 & 154 & 90 & 25 & 101 & 211 & 0 & 142 & 132 & 93 & 92 \\
\hline 10 & 35 & 26 & 97 & 59 & 53 & 132 & 16 & 122 & 142 & 50 & 5 & 85 & 117 \\
\hline 11 & 36 & 40 & 81 & 83 & 51 & 113 & 9 & 65 & 132 & 85 & 0 & 90 & 80 \\
\hline 12 & 71 & 79 & 52 & 73 & 82 & 91 & 101 & 103 & 93 & 85 & 90 & 0 & 39 \\
\hline 13 & 63 & 83 & 52 & 72 & 53 & 70 & 108 & 100 & 92 & 117 & 80 & 39 & 0 \\
\hline
\end{tabular}

Table 12. Coordinates of candidate sites $\left(X_{i}, Y_{i}\right)$.

\begin{tabular}{llllllllllllll}
\hline Soordinates & $\mathbf{1}$ & $\mathbf{2}$ & $\mathbf{3}$ & $\mathbf{4}$ & $\mathbf{5}$ & $\mathbf{6}$ & $\mathbf{7}$ & $\mathbf{8}$ & $\mathbf{9}$ & $\mathbf{1 0}$ & $\mathbf{1 1}$ & $\mathbf{1 2}$ & $\mathbf{1 3}$ \\
\hline Longitude & 40 & 78 & 61 & 10 & 55 & 89 & 73 & 7 & 80 & 68 & 72 & 12 \\
Latitude & 6 & 34 & 74 & 13 & 49 & 80 & 5 & 9 & 94 & 13 & 11 & 64 & 65 \\
\hline
\end{tabular}

Table 13. Dysfunction costs $\left(N_{i k}\right)$.

\begin{tabular}{|c|c|c|c|c|c|c|}
\hline Site & Facility Type & 2 & 3 & 4 & 5 & 6 \\
\hline 1 & 150 & 156 & 127 & 145 & 122 & 120 \\
\hline 2 & 143 & 128 & 102 & 152 & 107 & 164 \\
\hline 3 & 156 & 120 & 144 & 143 & 138 & 141 \\
\hline 4 & 126 & 163 & 108 & 149 & 146 & 144 \\
\hline 5 & 165 & 161 & 127 & 134 & 143 & 153 \\
\hline 6 & 142 & 134 & 128 & 159 & 126 & 149 \\
\hline 7 & 114 & 119 & 115 & 152 & 119 & 146 \\
\hline 8 & 129 & 135 & 116 & 153 & 147 & 120 \\
\hline 9 & 111 & 142 & 141 & 139 & 101 & 133 \\
\hline 10 & 137 & 134 & 152 & 152 & 156 & 158 \\
\hline 11 & 112 & 104 & 145 & 161 & 103 & 108 \\
\hline 12 & 115 & 123 & 161 & 155 & 135 & 159 \\
\hline 13 & 110 & 121 & 111 & 143 & 130 & 113 \\
\hline
\end{tabular}

The model solved for above example and results illustrated in table 14. The results are compared for both formulation (developed formulation and Karbasian \& abedi [18]).

Table 14. Results.

\begin{tabular}{|c|c|c|c|c|c|c|c|}
\hline & Obj. 1 & Obj. 2 & Obj. 3 & Obj. 4 & Obj. 5 & Obj. 6 & Time To solve \\
\hline Developed Model & 1091 & 1216 & 8652 & 0.342 & 4012 & 5307 & 25 \\
\hline Karbasian \& Abedi & 2912 & 2686 & 13394 & 0.34 & 6160 & 6782 & 14 \\
\hline
\end{tabular}

Results show that by adding new objective to the model, first objective decreased but other objectives increased. So the new objective is in line with four objectives of the old model. It can be said that the proposed model will be better than old model in two aspects: 1- increasing objectives and 2considering costs of attack.

\section{Conclusions}

Since the objectives and main principles of site selection's passive defense of the facility are reducing the possibility and the costs of the damage of the total network created by the site selection's facility, in this paper the presented model can select the sites in a manner that not only it maximizes the security coefficient of created network to perform its duty but also minimizes the possibility of identification of it by the enemy. At the same time, the proposed model helps the system to achieve its maximum reliability when attacked by the enemy. What is interesting in this model is to access the above purposes 
with minimum site selection cost and minimum expected cost of attack to the facilities of this network that is one of the main purposes of the passive defense. Also a method for solving the proposed model that uses the Genetic algorithm integrated with TOPSIS is proposed and then shows that the proposed method is good for solving Multi-objective constrained models.

This paper proposed its model only in site selection of strategic facilities. It is suggested to be used for locating all kind of military and civilian facilities and also industrial location especially critical facilities. This model also is capable of being applied in land use planning. The proposed model has been designed to increase the necessities of the factories using the obnoxious facilities.

\section{References}

[1] A. Ahmadi-Javid, P. Seyedi, S. S. Syam, A survey of healthcare facility location, Computers \& Operations Research, 79 (2017) 223-263.

[2] A. Ahmadi, M. S. Pishvaee, M. R. Akbari Jokar, A survey on multi-floor facility layout problems, Computers \& Industrial Engineering, 107 (2017) 158-170.

[3] L. Alçada-Almeida, J. Coutinho-Rodrigues, J. Current, A multiobjective modeling approach to locating incinerators, Socio-Economic Planning Sciences, 43 (2009) 111-120.

[4] O. Berman, A. Gavious, Location of terror response facilities: A game between state and terrorist, European Journal of Operational Research, 177 (2007) 1113-1133.

[5] O. Berman, Q. Wang, Locating a semi-obnoxious facility with expropriation, Computers \& Operations Research, 35 (2008) 392-403.

[6] J. A. Bullock, G. D. Haddow, D. P. Coppola, 3 - Hazards, in: Homeland Security (Second Edition), ButterworthHeinemann, 2018, pp. 45-66.

[7] R. L. Church, R. S. Garfinkel, Locating an obnoxious facility on a network, Transportation science, 12 (1978) 107-118.

[8] R. L. Church, A. T. Murray, Business Site Selection, Location Analysis and GIS, (2008).

[9] K. M. Curtin, R. L. Church, A Family of Location Models for Multiple - Type Discrete Dispersion, Geographical Analysis, 38 (2006) 248-270.

[10] K. Deb, K. Miettinen, Multiobjective optimization: interactive and evolutionary approaches, Springer Science \& Business Media, 2008.

[11] Z. Drezner, H. W. Hamacher, Facility location, SpringerVerlag New York, NY, 1995.

[12] Z. Drezner, H. W. Hamacher, Facility location: applications and theory, Springer Science \& Business Media, 2001.
[13] Z. Drezner, G. O. Wesolowsky, Location of multiple obnoxious facilities, Transportation Science, 19 (1985) 193202.

[14] Z. Drezner, G. O. Wesolowsky, Obnoxious facility location in the interior of a planar network, Journal of Regional Science, 35 (1995) 675-688.

[15] E. Erkut, S. Neuman, Analytical models for locating undesirable facilities, European Journal of Operational Research, 40 (1989) 275-291.

[16] A. Giostri, M. Binotti, E. Macchi, Microalgae cofiring in coal power plants: Innovative system layout and energy analysis, Renewable Energy, 95 (2016) 449-464.

[17] P. Hou, W. Hu, C. Chen, M. Soltani, Z. Chen, Optimization of offshore wind farm layout in restricted zones, Energy, 113 (2016) 487-496.

[18] M. Karbasian, S. Abedi, A Multiple Objective Nonlinear Programming Model for Site Selection of the Facilities Based on the Passive Defense Principles, International Journal of Industrial Engineering and Production Research, 22 (2011) 243-250.

[19] M. Kühmaier, G. Erber, C. Kanzian, F. Holzleitner, K. Stampfer, Comparison of costs of different terminal layouts for fuel wood storage, Renewable Energy, 87, Part 1 (2016) 544-551.

[20] J. Movahedniya, The Principles and Basis of Passive Defense, First Edition ed., Malik Ashtar University of Tech., Tehran, 2007.

[21] A. T. Murray, R. L. Church, R. A. Gerrard, W. S. Tsui, Impact models for siting undesirable facilities, Papers in regional science, 77 (1998) 19-36.

[22] J. Rakas, D. Teodorović, T. Kim, Multi-objective modeling for determining location of undesirable facilities, Transportation Research Part D: Transport and Environment, 9 (2004) 125138 .

[23] B. Roy, Multicriteria methodology for decision aiding, Springer Science \& Business Media, 2013.

[24] H. Shamsi, Logistics and Site Selection, First Edition ed., Malik Ashtar University of Tech., Tehran, 2007.

[25] H. Skade, ALFRED WEBER's Theory of the location of industries, in: Nationaløkonomisk Tidsskrift, The University Chicago, Chicago, 1929.

[26] J. H. Sorensen, J. Soderstrom, S. A. Carnes, Sweet for the sour: incentives in environmental mediation, Environmental Management, 8 (1984) 287-294.

[27] A. A. Taleizadeh, S. T. A. Niaki, M.-B. Aryanezhad, A hybrid method of Pareto, TOPSIS and genetic algorithm to optimize multi-product multi-constraint inventory control systems with random fuzzy replenishments, Mathematical and Computer Modelling, 49 (2009) 1044-1057.

[28] G. Wesolowski, The Weber problem: History and perspective, Location Science, 1 (1993) 5-23. 